\title{
Implicações Da Investigação Matemática No Espaço Educacional Com A Inserção Das Tecnologias Digitais
}

\section{Implications of Mathematical Research in Educational Space with the Instrument of Digital Technologies}

\author{
Aline de Lima Brum* \\ Universidade Federal do Rio Grande - FURG \\ Elaine Corrêa Pereira** \\ Universidade Federal do Rio Grande - FURG
}

\begin{abstract}
Resumo
Este artigo tem por objetivo discutir o potencial de uma prática pedagógica que inseriu smartphones, o site de rede social Facebook, o aplicativo WhatsApp e o software GeoGebra nas aulas de Matemática. Apresentamos as contribuições teóricas de Ponte, Brocardo e Oliveira (2016), Moran e Behrens (2013) e Imbernón (2011). O presente estudo de abordagem qualitativa relata os resultados de uma pesquisa de mestrado com uma turma de nono ano, do Ensino Fundamental, de uma escola da rede pública no município de Rio Grande/RS, no período de março a dezembro de 2016. Adotamos para a análise dos dados o método da Análise Textual Discursiva, proposta por Moraes e Galiazzi (2011). A partir desse processo, foram elaborados três metatextos, dos quais abordaremos - Tecnologia e Matemática: um novo olhar para a Matemática que transcende os muros da escola. Dessa maneira, os avanços e potencialidades percebidas nesse estudo mostraram que as tecnologias digitais proporcionaram interações nos espaços de aprendizagem presencial e digital, ampliando as possibilidades de construção do conhecimento matemático, suscitando implicações para a prática pedagógica e novos olhares para a investigação Matemática dentro e fora da sala de aula.
\end{abstract}

Palavras-chave: Investigação Matemática; Tecnologias Digitais; Ensino; Aprendizagem

\begin{abstract}
This article aims to discuss the potential of a pedagogical practice that inserted smartphones, the social networking site Facebook, the WhatsApp application and the GeoGebra software in Mathematics classes. We present the theoretical contributions of Ponte, Brocardo and Oliveira (2016), Moran and Behrens (2013) and Imbernón (2011). The present qualitative study reports the results of a master's study with a ninth grade class from Elementary School from a public school in the municipality of Rio Grande / RS, from March to December 2016. We adopted the analysis of the data the Discursive Textual Analysis method, proposed by Moraes and Galiazzi (2011). From this process, three metatexts were elaborated, of which we will approach - Technology and Mathematics: a new look at Mathematics that transcends the school walls. In this way, the advances and potentialities perceived in this study showed that digital technologies provided interactions in the online and digital learning spaces, expanding the possibilities of construction of mathematical knowledge, eliciting

\footnotetext{
* Doutoranda no Programa de Educação em Ciências: Química da Vida e Saúde pela Universidade Federal do Rio Grande (FURG). Mestra em Educação em Ciências (FURG). Professora de Matemática da rede municipal de ensino, Rio Grande, RS, Brasil. E-mail: alinebeta@yahoo.com.br

${ }^{* *}$ Pós-Doutora pela Universidade Eduardo Mondlane (UEM), Moçambique. Professora Associada da Universidade Federal do Rio Grande (FURG), na área de Álgebra, Análise e Matemática Discreta no Instituto de Matemática, Estatística e Física - IMEF, Rio Grande, RS, Brasil. E-mail: elainepereira@prolic.furg.br
} 
implications for pedagogical practice and new perspectives for mathematical research inside and outside of the classroom.

Keywords: Mathematical Research; Digital Technologies; Teaching; Learning

\section{Introdução}

Acordar ao som da sua música preferida ou por outro toque selecionado em seu smartphone é o primeiro contato que a maioria das pessoas compartilha ao despertar de um novo dia. Na sequência, antes mesmo de realizar a higiene pessoal e pensar no café da manhã, podemos checar nossos e-mails, os likes nos sites de redes sociais, verificar as mensagens de "bom dia", que simplesmente se multiplicam nos grupos de aplicativos, acessar a conta bancária, ler um livro digital ou assistir um filme. O smartphone, que representa um bem de consumo democrático, a medida que, pessoas de todas as idades e classes sociais tem acesso a esse dispositivo, tornou-se uma extensão do próprio corpo.

A geração conectada, ou seja, aquela que se permite estar em vários espaços digitais ao mesmo tempo tem um fascínio por Stories ${ }^{l}$, não só por compartilhar as suas, mas também de conhecer as histórias dos seus amigos. A conectividade possibilita viver no espaço virtual uma rede de interconexões com pessoas próximas e distantes, em um universo colorido, com mensagens de otimismo e a riqueza de aplicativos de produção e compartilhamento de fotos e vídeos que podem ser editados com filtros, emojis ou textos.

Como poderíamos imaginar que atividades rotineiras pudessem ser transmitidas no perfil de forma criativa, com posts de uma história que evidencia a nossa personalidade, nossos gostos e os momentos especiais que partilhamos com os que amamos. A era digital surpreende com inovações tecnológicas que estão ao alcance das nossas crianças, jovens e adultos. Fugir dessa geração conectada não é mais permitido, eles invadiram as escolas, são professores, alunos e demais funcionários. É uma rede que se expande, se junta e prolifera em todos os ramos da sociedade informatizada.

O potencial pedagógico das tecnologias digitais é perscrutado neste artigo que oferece contribuições teóricas, metodológicas e empíricas, a partir de uma pesquisa de mestrado realizada com 24 estudantes do nono ano do Ensino Fundamental de uma escola da rede pública, no município de Rio Grande/RS, no período de março a dezembro de 2016. As

\footnotetext{
${ }^{1}$ Stories é um novo recurso disponível nos sites de rede sociais Facebook e Instagram, que permite aos usuários a possibilidade de compartilhar fotos ou vídeos curtos que desaparecem após 24 horas de sua publicação. Disponível em: <https://postcron.com/pt/blog/instagram-stories/>. Acesso em: 18 Jan. 2018.
} 
atividades desenvolvidas com a turma emergiram da necessidade de reconstruir práticas do cotidiano com os dispositivos móveis, na produção de vídeos e construção de histórias matemáticas, utilizando como recurso didático a leitura do livro O Diabo dos Números, do escritor alemão Hans Magnus Enzensberger.

Com base nessas histórias criadas pelos próprios alunos descobrimos o impacto da Matemática em suas vidas e exploramos alguns passos da investigação Matemática proposta por Ponte, Brocardo e Oliveira (2016) que se apresenta como uma poderosa forma de construir o conhecimento. Moran (2013) infere que o ambiente escolar viverá novos tempos de aprendizagem transformando-se em espaços de aprendizagem colaborativa e personalizada. Nesse sentido, Behrens (2013) enfatiza os novos papéis que professores e alunos assumem na produção do conhecimento em um processo intitulado de aprender a aprender. E finalmente, Imbernón (2011), refere-se a complexidade de pôr em prática uma inovação que pode ser superada quando interiorizamos, adaptamos e experimentamos práticas pedagógicas reais em nossa formação.

Tendo em vista as contribuições teóricas que tecem este estudo, o objetivo deste artigo é discutir o potencial de uma prática pedagógica que inseriu smartphones, o site de rede social Facebook, o aplicativo WhatsApp e o software GeoGebra nas aulas de Matemática. Adotamos como metodologia a Análise Textual Discursiva (ATD), proposta por Moraes e Galiazzi (2011), por ser de abordagem qualitativa e possibilitar a expressão de novos sentidos sobre o fenômeno investigado.

\section{O Potencial Pedagógico Das Tecnologias Digitais No Desenvolvimento Da Investigação Matemática}

Novas abordagens dependem da intencionalidade do educador, de reconhecer o seu papel no ensino, que além de repensar a prática pedagógica, seja capaz de modificá-la. Houve um tempo em que se pensava que a tecnologia substituiria o professor. Conforme afirmam Borba e Penteado (2010, p. 55), "no final da década de 70, quando teve início a discussão sobre o uso de tecnologia informática na educação, imaginava-se que uma das implicações de sua inserção na escola seria o desemprego de professores".

Com o passar do tempo, a inserção das tecnologias digitais na sala de aula trouxe novos desafios ao professor, que além de dominar o seu conteúdo, precisará estar em constante atualização com os softwares disponíveis e, ao mesmo tempo, lidar com situações 
inesperadas. Nem sempre o professor terá todas as respostas, os alunos estão em contato direto com essas tecnologias e podem trazer situações novas, dúvidas e certezas. Talvez seja por isso que alguns educadores tem receio em integrar as tecnologias à prática docente.

O professor que já tem seu planejamento, exercícios resolvidos, livros previamente selecionados para atividades em sala de aula e para provas, que vive na zona de conforto, dominando o conteúdo e tendo as respostas prontas, se vê desafiado a trilhar a zona de risco. Dessa maneira, o educador se beneficiará das potencialidades das tecnologias no processo de ensino e aprendizagem, no qual todos os sujeitos envolvidos interagem e crescem juntos (BORBA; PENTEADO, 2010).

A integração de tecnologias ao processo educativo não pode ser concebida de maneira superficial como mera transmissão de conteúdo. Há de se ter um equilíbrio entre o que é proposto nos currículos e as reais necessidades dos alunos. Podemos observar que no dia a dia os estudantes vivem conectados à internet, enquanto na escola seu uso é proibido. De acordo com Kenski:

\begin{abstract}
A necessidade, portanto, não é de usar o meio para continuar fazendo o mesmo. É preciso mudar as práticas e os hábitos docentes e aprender a trabalhar pedagogicamente de forma lúdica e desafiadora, com o apoio e a mediação de softwares, programas especiais e ambientes virtuais. Em princípio, devemos compreender e nos apropriar das especificidades das inovações tecnológicas, adequando-as como inovações pedagógicas. (KENSKI, 2013, p.97)
\end{abstract}

Nessa perspectiva, acreditamos que a discussão sobre as tecnologias na educação matemática deva ser compreendida para não se perder de vista a finalidade maior da educação que, para Belloni (2009), é formar o cidadão competente para a vida em sociedade promovendo a apropriação crítica e criativa destas tecnologias pelo professor e pelo aluno. Ainda de acordo com a autora, a integração das tecnologias digitais à educação só faz sentido se realizada em sua dupla dimensão - como ferramenta pedagógica e como objeto de estudo para que possamos adequar métodos e estratégias de ensino.

O educador precisa criar estratégias que valorizem a construção do conhecimento de maneira colaborativa e mais participativa. De acordo com Moran (2013, p. 29), "aprendemos também pelo estímulo, pela motivação de alguém que nos mostra que vale a pena investir no que estudamos. Aprendemos pelo prazer, porque gostamos de um assunto, de uma mídia, de uma pessoa". As mudanças na educação dependem do educador, mas também dependem muito do aluno, da vontade de aprender e suscitar no professor-educador o espírito de pesquisador, que busca a compreensão e o sentido do trabalho que desenvolve. A seguir, 
apresentamos os instrumentos para a produção dos dados e algumas das práticas pedagógicas desenvolvidas com a turma.

\section{Produção dos Dados}

A cada prática pedagógica desenvolvida na sala de aula da pesquisadora, propomos estratégias que pudessem contribuir para investigar a dinâmica e as possibilidades de mudanças no ensinar e aprender Matemática com a inserção das tecnologias digitais. Foram utilizados como instrumentos da produção dos dados o Diário da Pesquisadora, um Portfólio Virtual construído com os alunos no Facebook e um Grupo no WhatsApp, para a compreensão do fenômeno estudado.

As percepções sobre as construções de conceitos matemáticos, a motivação da turma no desempenho e na elaboração de ações educativas com o uso das tecnologias foram registradas no Diário da Pesquisadora. O Portfólio Virtual no Facebook é uma ferramenta proposta pela pesquisadora e desenvolvida a distância pela turma. Nesse espaço os alunos registraram as reflexões sobre as aprendizagens, as dificuldades, os anseios e as descobertas. E o papel da educadora é o de orientar nesse processo e auxiliar na organização das ideias, como podemos observar os questionamentos ilustrados na figura 1.

\section{Aline Brum}

17 de maio de 2016 . Adicionar tópicos

\section{O Portfólio vai ser o nosso diário!!!}

Vamos começar relatando um pouquinho da experiência de construir um vídeo em grupo sobre "A Matemática e as formas geométricas no dia a dia de vocês"!

Para construir este relato vou lançar alguns questionamentos:

a) Como foi a experiência de elaborar um vídeo com os colegas, envolvendo a disciplina de Matemática?

b) Vocês elaboraram um roteiro, com alguns passos que deveriam seguir e os lugares que gostariam de filmar?

c) O grupo conseguiu fazer o trabalho no mesmo dia?

d) Todos colaboraram com a realização do vídeo?

e) Quais foram as aprendizagens mais importantes na tua opinião?

f) Em algum momento surgiram dúvidas sobre as formas geométricas?

g) Quem editou o vídeo? Qual programa utilizou? Teve alguma dificuldade?

h) Tu acreditas que a realização deste vídeo contribuiu para a tua aprendizagem na disciplina de Matemática?

Essas perguntas não precisam ser respondidas na ordem em que aparecem. Elas servem para ajudar na escrita do relato!!!

Qualquer dúvida é só perguntar!!! :-

Vamos adicionar os amigos que ainda não fazem parte do grupo!!!

Beijão!!! $\because \odot \odot$

Figura 1 - Atividade de Escrita no Portfólio Virtual 
Outra estratégia que favoreceu a aprendizagem colaborativa foi a criação de um grupo no WhatsApp para interagir com os alunos de forma mais rápida. Nesse espaço, a pesquisadora estimulou a participação de todos enviando mensagens e materiais que orientassem as próximas práticas pedagógicas e os estudantes postaram os resultados das investigações produzidas, assim como os vídeos. O vídeo pode ser uma importante ferramenta no processo de ensino e aprendizagem para introduzir um conteúdo novo, motivar e despertar a curiosidade dos estudantes, aproximando-os de realidades distantes. Moran (2013) explora algumas formas de utilização criativa do vídeo para sensibilizar os alunos, afirmando que os celulares mais avançados, como os smartphones, são poderosos dispositivos que permitem a professores e alunos produzirem vídeos de maneira divertida, rápida e fácil de editar e enviar ao YouTube ou outro site.

De acordo com Moran (2013), com as tecnologias móveis, qualquer um pode ser produtor e transmissor de um vídeo digital. Esse autor enfatiza que as escolas ainda não reconhecem as potencialidades oferecidas por essas tecnologias para que os alunos se transformem em autores e contadores de histórias.

Os jovens adoram fazer vídeo, e a escola precisa incentivar ao máximo a produção de pesquisas em vídeo pelos alunos. A produção em vídeo tem uma dimensão moderna, lúdica. Moderna, como um meio contemporâneo, novo, que integra linguagens. Lúdica, pela miniaturização da câmera, que permite brincar com a realidade, levá-la junto para qualquer lugar. Filmar é uma das experiências mais envolventes, tanto para crianças como para adultos. (MORAN, 2013, p. 48)

Nesse sentido, os alunos foram incentivados a produzir um vídeo sobre as formas geométricas no seu dia a dia, utilizando os seus smartphones. A proposta da pesquisadora consistiu na exploração de ambientes ou locais que fizessem parte da vivência dos alunos, ou seja, o trajeto percorrido da casa até a escola, o quarto deles ou algum lugar predeterminado pelo grupo. As produções dos vídeos sobre o tema "Pesquisando as formas geométricas no meu dia a dia" envolveu a criatividade dos alunos, um trabalho em grupo com diversão, música, dança e entrevistas na rua. Cada grupo se destacou pela sua originalidade e espírito de equipe, explorando alguns pontos turísticos da nossa cidade e reconhecendo as formas geométricas no seu cotidiano.

Aliado a elaboração do vídeo utilizamos como recurso didático pedagógico a leitura do livro O Diabo dos Números. Este livro conta a história de um menino de onze anos, que usa um pijama azul e tem pesadelos a noite. O menino atende pelo nome de Robert e vive 
fascinantes aventuras em seus sonhos mirabolantes. Um dia Robert sonha que é engolido por um peixe, no outro desce de um escorregador gigante, e às vezes, quando deseja muito um presente, chega a sonhar que está chegando bem perto dele, e o tal presente desaparece.

Certo dia, Robert andava intrigado com esses pesadelos e apareceu no seu sonho o Teplotaxl, também conhecido como o diabo dos números. Na verdade ele não era tão aterrorizante assim, sua fisionomia era de um senhor bem velho e baixinho com uma bengala. Em uma sequência de doze sonhos, Robert e Teplotaxl encontram-se em diferentes lugares e vivenciam as mais belas aventuras envolvendo os números, a geometria, a calculadora, etc. Nas suas conversas com Teplotaxl, Robert começa a gostar de Matemática, porque o diabo mostra um lado diferente dessa disciplina e traduz o pensamento matemático para "língua de gente". O menino do pijama azul começa a dormir mais cedo, na expectativa de sonhar com o diabo dos números. E esse diabo, que no início, parecia descontrolado e sem paciência vai se tornar um grande amigo de Robert, demonstrando seu lado divertido e amoroso.

Essas histórias vividas por Robert e Teplotaxl inspiraram atividades sobre o medo que sentimos da Matemática quando estamos na escola e apresentamos dificuldades em relação a algum conteúdo. A turma foi dividida em duplas e cada uma ficou responsável pela leitura de um capítulo do livro, ou seja, cada dupla explorou as aventuras dos sonhos de Robert com o diabo dos números e em grupos criaram a sua própria história. A prática pedagógica desenvolvida consistiu na produção de um vídeo, intitulado: "Brincando com o Diabo dos Números", no qual os estudantes poderiam reproduzir cenas do livro adaptadas a sua realidade e aos seus medos de aprender Matemática na escola. A atividade de escrita reflexiva proposta aos alunos sobre a produção desse vídeo pode ser observada na figura 2 .

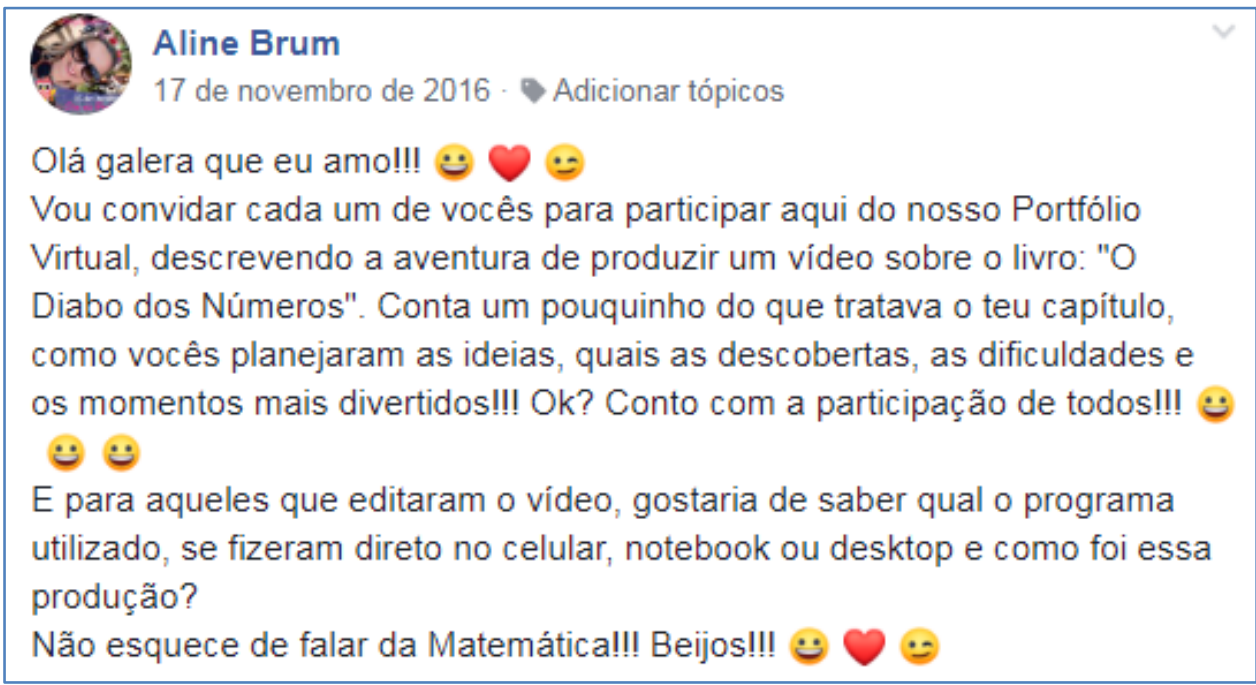

Figura 2 - Descrição no Portfólio Virtual Fonte: Arquivo das autoras 
Diante desse contexto, Menezes (2011) reconhece o mérito da inclusão da literatura alusiva à Matemática enquanto recurso didático, que mesmo sendo uma combinação pouco explorada nas escolas, "pode criar condições para que os alunos interajam e discutam o significado do que leem, contribuindo para o desenvolvimento do conhecimento e das capacidades matemáticas dos alunos" (MENEZES, 2011, p.71). Para tanto, essas histórias produzidas em vídeo com aporte literário, subsidiaram outras estratégias de investigação Matemática utilizando o software de geometria dinâmica GeoGebra na visualização e construção de conjecturas.

\section{Análise dos Dados}

Para analisar os dados produzidos, adotamos o método da Análise Textual Discursiva proposta por Moraes e Galiazzi (2011). Essa metodologia foi escolhida por ser de abordagem qualitativa e permitir a compreensão do fenômeno investigado no ambiente educativo. De acordo com Moraes e Galiazzi (2011, p. 14), “a análise textual discursiva propõe-se a descrever e interpretar alguns dos sentidos que a leitura de um conjunto de textos pode suscitar". Nesse sentido, partindo do pressuposto de que a ATD opera com significados construídos a partir de um conjunto de textos que possibilitam múltiplas interpretações, tomaremos como corpus da análise as produções textuais dos alunos construídas no Portfólio Virtual. De acordo com Moraes e Galiazzi:

O corpus da análise textual, sua matéria-prima, é constituído essencialmente de produções textuais. Os textos são entendidos como produções linguísticas, referentes a determinado fenômeno e originadas em um determinado tempo e contexto. (MORAES; GALIAZZI, 2011, p. 16)

O primeiro passo da análise textual discursiva é a desconstrução e unitarização dos textos do corpus. Convém destacar que na leitura das produções dos alunos podemos atribuir diferentes significados, o que caracteriza o exercício de uma atitude fenomenológica, que para Moraes e Galiazzi (2011, p. 14), "representa um esforço de colocar entre parênteses as próprias ideias e teorias e exercitar uma leitura a partir da perspectiva do outro". Entendemos que o pesquisador atribui significados aos textos que compõem o corpus influenciado pelas concepções de educação, conhecimento, embasamento teórico e as experiências vividas no campo empírico.

A partir das leituras iniciais, começamos a fragmentação das reflexões produzidas pelos alunos no Portfólio Virtual, no sentido de atingir pequenas unidades de significado, 
processo denominado por Moraes e Galiazzi (2011) de unitarização:

O momento da unitarização é um movimento desconstrutivo. Consiste numa explosão de ideias, uma imersão no fenômeno investigado, por meio do recorte e discriminação de elementos de base, tendo sempre como ponto de partida os textos constituintes do "corpus". (MORAES; GALIAZZI, 2011, p. 49)

Assim sendo, a construção das unidades de significado constitui-se em um movimento de impregnação do pesquisador com os textos propiciando um processo de desorganização e o estabelecimento de novas relações sobre o fenômeno investigado. Após a desconstrução do corpus em unidades de significado, foram feitas as categorizações, que representam o segundo passo da ATD. Para a construção das categorias, inicialmente, agrupamos as unidades de significado semelhantes, originando as categorias iniciais, que aproximadas, possibilitaram a elaboração das categorias intermediárias, a partir de um processo recursivo de análise da pesquisadora. E, em um novo esforço construtivo de escuta do que ainda se aproximava, emergiram as categorias finais acerca do fenômeno investigado.

Por fim, para completar o ciclo de análise, apresentamos o terceiro passo da ATD, que consiste na construção do metatexto, ou seja, na comunicação das novas compreensões atingidas. Resultante desse processo, produzimos os metatextos intitulados: "As tecnologias digitais como parte do processo de educação do elemento humano (aluno e professor)", “Construção de novos espaços de aprendizagem com a inserção dos dispositivos móveis" e "Tecnologia e Matemática: um novo olhar para a Matemática que transcende os muros da escola”. Nesse artigo, apresentamos os resultados do terceiro metatexto.

\section{Resultados}

O metatexto intitulado "Tecnologia e Matemática: um novo olhar para a Matemática que transcende os muros da escola" representa um recorte da análise das compreensões emergentes sobre o fenômeno investigado. No contexto do ensino e da aprendizagem, o presente estudo transcorrerá sobre as práticas de investigação matemática que transcenderam a sala de aula. Essa questão suscita pensar no sentido atribuído a palavra transcender, do latim transcendere, em uma de suas acepções no Dicionário Aurélio, que remete a passar além; ultrapassar (FERREIRA, 2010, p. 2068). Para compreender a verdadeira natureza da Matemática, precisamos abandonar velhas convicções de que essa ciência está pronta e ampliar nosso entendimento, em uma perspectiva dinâmica que possibilita a investigação e a construção de conceitos matemáticos. 
Ponte, Brocardo e Oliveira (2016, p. 13) afirmam que investigar para os matemáticos "é descobrir relações entre objetos matemáticos conhecidos ou desconhecidos, procurando identificar as respectivas propriedades". Outro ponto importante destacado pelos autores é que uma investigação matemática não precisa abordar problemas difíceis, mas trabalhar com questões que nos interpelam e provocam a busca por respostas que não estão prontas. Para entender como podemos realizar uma investigação matemática na sala de aula, precisamos desenvolver três fases (em uma aula ou conjunto de aulas), que consistem em:

(i) introdução da tarefa, em que o professor faz a proposta a turma, oralmente ou por escrito, (ii) realização da investigação, individualmente, aos pares, em pequenos grupos ou com toda turma, e (iii) discussão dos resultados, em que os alunos relatam aos colegas o trabalho realizado. (PONTE; BROCARDO; OLIVEIRA, 2016, p. 23)

Essas fases podem ser realizadas de diferentes maneiras, de acordo com a intencionalidade do professor, tendo sempre em vista que podemos planejar o modo de começar uma investigação, mas poderemos nos surpreender com os resultados. No início, a primeira etapa, o professor conversa com a turma e expõe a proposta de trabalho, conscientizando os participantes da colaboração de cada um na realização da investigação. $\mathrm{Na}$ segunda etapa, os alunos se dividem em grupos, de preferência por afinidades, para que o trabalho desenvolvido represente a personalidade de cada integrante, facilitando a organização e divisão das tarefas. $\mathrm{O}$ aluno precisa se sentir motivado para discutir suas ideias com o professor e com os colegas, estabelecendo uma parceria no ambiente de aprendizagem e, consequentemente, a valorização do seu trabalho. Por fim, a terceira etapa, representa a divulgação dos resultados dos grupos para a turma, que pode ser feito de modo presencial, na sala de aula, ou utilizando um ambiente virtual de aprendizagem.

Tomemos como exemplo as falas dos estudantes ${ }^{2}$ sobre a investigação realizada: "Eu achei uma experiência muito legal e diferente, mesmo já conhecendo as formas geométricas, tive um outro olhar para as coisas na rua e foi um jeito de aprender mais" (TASHA, 2016). O aluno Hulk afirma que: "a principal aprendizagem foi que a matemática não está só dentro da sala de aula, nós convivemos com a matemática e não percebemos" (HULK, 2016). Nesse sentido, a aluna Açúria contribui: "Elaborar um vídeo para o trabalho de matemática foi muito legal, pude aprender mais sobre geometria, além de perceber o quanto a matemática está presente no nosso dia-a-dia" (AÇÚRIA, 2016).

\footnotetext{
${ }^{2}$ Os nomes dos estudantes são fictícios para preservar as suas identidades. A proposta era escolher um nome que representasse a sua interação no meio digital, poderia ser um login utilizado em aplicativos ou uma palavra referente ao ensino de Matemática.
} 
Esta percepção de que a Matemática está presente em todos os segmentos de nossas vidas é expressa pela maioria dos alunos na fase inicial da investigação, a qual se destaca como decisiva na elaboração e construção de conjecturas. É nessa fase que os alunos vão se familiarizando com o ambiente que os cercam e fazendo relações do que se aprende dentro e fora da sala de aula. Nessa perspectiva Moran (2013) enfatiza que:

É importante conectar sempre o ensino com a vida do aluno. Chegar ao aluno por todos os caminhos possíveis: pela experiência, pela imagem, pelo som, pela representação (dramatizações, simulações), pela multimídia, pela interação on-line e off-line. (MORAN, 2013, p. 69)

Moran alerta que viveremos novos tempos de aprendizagem em sala de aula, priorizando a pesquisa em tempo real, atividades individuais e grupais on-line, transformando o ambiente escolar em espaços de aprendizagem colaborativa e personalizada. Ponte, Brocardo e Oliveira (2016, p. 26) afirmam que o trabalho em grupo "potencia o surgimento de várias alternativas para a exploração da tarefa". No entanto, se os alunos não estão acostumados a trabalhar em grupo e realizar investigações, a inserção desses dois elementos novos pode gerar alguns conflitos que necessitam da intervenção docente. Sobre a dinâmica do trabalho em grupo, destacamos a fala da estudante Delta:

Tivemos uma certa dificuldade em questão do roteiro, não fazíamos ideia do que fazer. Outro problema que tivemos foi pra começarmos a gravar, as ideias foram surgindo bem no final do tempo dado pela professora, então a correria de gravar foi um pouco tensa. Gravamos em 2 dias seguidos, sexta e sábado, a tarde inteira. Aconteceram alguns desencontros e indisponibilidades de horários na sexta-feira, mas no sábado conseguimos gravar tudo sem nenhum problema. (DELTA, 2016)

Nesse grupo, a aluna destaca a dificuldade de elaborar um roteiro para a gravação do vídeo, mesmo tendo os capítulos do livro O Diabo dos Números, não conseguiam organizar as ideias mais importantes. Com o prazo de entrega se aproximando, os alunos organizaram-se em dois dias e concluíram o vídeo. Outro ponto evidenciado pela aluna diz respeito à motivação e à participação de todos na realização da atividade: "Gravar foi um pouco difícil porque ficávamos rindo o tempo inteiro, algumas cenas (principalmente a do diabo) foram muito engraçadas. Todos colaboraram, participaram e ajudaram em cada parte da gravação" (DELTA, 2016). Delta relata ainda: "Sinceramente, me surpreendi muito com o resultado do vídeo e com a participação e colaboração de todos para o mesmo" (DELTA, 2016).

Como podemos observar, com base nos relatos apresentados, o papel do professor como orientador nesse processo é fundamental, estimulando a colaboração e ajuda mútua, fazendo os alunos refletirem sobre a investigação, registrando suas dificuldades, descobertas e novas aprendizagens. Esse processo de reflexão ajuda a compreender as estratégias utilizadas 
na construção de conjecturas. Contudo, a interação entre professores e alunos se diferencia das aulas tradicionais, revelando uma nova prática pedagógica mais dialógica, de modo que o aluno pode despertar aspectos desconhecidos pelo professor. Para tanto, precisamos estabelecer uma relação de confiança com nossos estudantes, propiciando ambientes de aprendizagem mais flexíveis que transcendam os muros da escola.

De acordo com Moran (2013), com o tempo fará sentido repensar os horários, os espaços e as formas de organizar os processos de ensino e aprendizagem:

É uma questão de amadurecimento e de profundo intercâmbio de experiências para construir propostas mais arrojadas, testadas e aceitas. Demorará mais do que gostaríamos, mas a chegada das tecnologias móveis às salas de aula é como um cavalo de Troia. Em curto prazo, parece que não haverá muitas mudanças; mas, em médio prazo, ela nos obrigará a reorganizar o tempo, o espaço e a forma de ensinar e aprender. (MORAN, 2013, p. 68)

Nesse novo contexto, em que buscamos reorganizar a prática pedagógica com a inserção dos dispositivos móveis na construção de conceitos matemáticos, observamos nas falas dos alunos a percepção de que a Matemática não se reduz aos cálculos:

Quando falam matemática eu só imagino contas e se falar em formas geométricas eu vou pensar em contas também, mas que envolvem formas, tipo o perímetro. Mas depois desse trabalho, eu vejo que as formas geométricas estão em todo lugar, fiquei muito impressionada com esse trabalho, pois achei que seria difícil achar formas geométricas, mas não, foi o oposto, pois assim que saímos para fazer o trabalho percebemos que praticamente tudo tinha uma forma geométrica. Foi o melhor trabalho que já fiz. (CARIOQUINHA, 2016)

Assim como a estudante Carioquinha, o aluno Betão também percebeu na realização do trabalho envolvendo as tecnologias digitais que: "A experiência de fazer um vídeo em matemática foi muito legal, pois nunca imaginei isso nessa matéria” (BETÃO, 2016). A motivação dos estudantes ao desenvolverem essas atividades suscita a busca de novas metodologias que atendam às exigências da sociedade informatizada. De acordo com Behrens (2013):

Em face da nova realidade, o professor deverá ultrapassar seu papel autoritário, de dono da verdade, para se tornar um investigador, um pesquisador do conhecimento crítico e reflexivo. O docente inovador precisa ser criativo, articulador e, principalmente, parceiro de seus alunos no processo de aprendizagem. Nessa nova visão, o professor deve mudar o foco do ensinar para reproduzir conhecimento e passar a preocupar-se com o aprender e, em especial, o "aprender a aprender", abrindo caminhos coletivos de busca e investigação para a produção do seu conhecimento e do seu aluno. (BEHRENS, 2013, p. 77)

$\mathrm{Na}$ visão dessa autora, os professores e alunos deveriam estar em um processo 
permanente de aprender a aprender, mudando o foco do ensinar para os caminhos que levem ao aprender. O professor que ainda acredita que o ensino para se concretizar necessita de uma quantidade substancial de informações com listas de exercícios repetidos recebe como retorno dos alunos o desinteresse nas aulas e, na maioria das vezes, eles nem se lembram do que estudaram na aula anterior. Essa realidade é identificada nas falas dos estudantes que valorizam o uso da tecnologia nas aulas de Matemática: "Para mim esse trabalho chegou para quebrar a rotina e sair do padrão de sala de aula, a proposta era fazer algo diferente de só copiar e fazer, e deu certo" (AO QUADRADO, 2016).

Nessa perspectiva, o aluno Bin Laden relata: "Curti bastante a aula com o geogebra, porque é um jeito diferente de aprender a matemática saindo dos exercícios no caderno que fica muitas vezes enjoativo (nada contra), enfim, foi bem show... tomara que tenha mais vezes" (BIN LADEN, 2016). Ao trabalhar com o software de geometria dinâmica GeoGebra, os alunos constroem objetos geométricos, experimentam e visualizam a Matemática em movimento, o que torna a aula mais interessante do que apenas fazer exercícios no caderno. A aluna Aqualien também gostou da aula com o GeoGebra: "Eu aprendi de uma maneira fácil, rápida e eficiente como utilizar as formas através do geogebra. Eu explorei bastante o aplicativo e achei bastante informações e outras formas geométricas, eu acho que deveríamos ter mais aulas como esta!" (AQUALIEN, 2016).

Além de considerar a aula diferente com a utilização do software e dos dispositivos móveis, os alunos valorizaram a investigação e as descobertas de novas ferramentas. Esses aspectos do processo investigativo podem ser observados na fala do aluno Mitchell:

\begin{abstract}
Passamos uma aula legal entre turma, onde aos poucos os risos e os aprendizados foram se misturando... Uma aula onde a força de vontade, a matemática e a diversão andaram de mãos dadas! Nos permitiu enxergar o quanto a tecnologia pode ajudar a entender melhor toda a parte da geometria! Eu amei fazer esse trabalho, pois vai muito além de apenas uma aula comum (em todos os sentidos) vou guardar tudo que estou aprendendo e todos esses momentos comigo... quando é a próxima? (MITCHELL, 2016)
\end{abstract}

Talvez esse seja o maior desafio do educador: perceber a matemática por meio dos olhos dos seus alunos, criando condições para que em parceria, professores e alunos transformem a sala de aula em um ambiente prazeroso de construção de conhecimentos, em uma interação inundada de afetividade. Mais uma vez, verificamos o quanto os alunos buscam integrar aos seus conhecimentos matemáticos a investigação e que o professor precisa estimular esse registro. De acordo com Ponte, Brocardo e Oliveira (2016, p. 30), "O professor precisa estar atento a todo esse processo de formulação e teste de conjecturas, para garantir que os alunos vão evoluindo na realização de investigações”. Desse modo, precisamos 
explorar diferentes assuntos possibilitando um novo olhar do aluno que o ajude a refletir sobre o que está fazendo, como exemplifica a aluna Tasha na construção do fractal utilizando o software GeoGebra:

Fractal é uma figura que pode ser quebrada em pequenos pedaços e pode se transformar em várias formas e fazer um desenho. Existe fractal na natureza, fractal abstrato, entre outros. Tentamos fazer um floco de neve usando geometria fractal. (TASHA, 2016)

Ponte, Brocardo e Oliveira (2016) reforçam o papel fundamental que o registro escrito desempenha quando realizamos uma investigação matemática, permitindo-nos acompanhar os avanços dos estudantes, a explicitação de suas ideias, a construção de conjecturas e a capacidade de se comunicarem matematicamente. Nesse caso, a aluna expressa o que observou na construção do floco de neve no GeoGebra, registra o seu entendimento sobre a geometria fractal e a percepção desses elementos na natureza. Ressaltamos que o professor deve estar preparado e consciente de que imprevistos acontecem, mas que podem ser superados a medida que o trabalho vai se desenvolvendo e consegue enxergar nos alunos o interesse e a motivação que há muito tempo se extinguiu. Nesse contexto, Imbernón (2011) afirma que a aquisição de conhecimentos por parte do professor é um processo amplo e não linear:

A mudança nas pessoas, assim como na educação, é muito lenta e nunca linear. Ninguém muda de um dia para o outro. A pessoa precisa interiorizar, adaptar e experimentar os aspectos novos que viveu em sua formação. A aquisição de conhecimentos deve ocorrer da forma mais interativa possível, refletindo sobre situações práticas reais. (IMBERNÓN, 2011, p. 16-17)

No decorrer de uma investigação, tanto aluno quanto professor aprende que cada pessoa tem o seu ritmo de aprendizagem e que "aprender para pôr em prática uma inovação supõe um processo complexo" (IMBERNÓN, 2011, p.17). Para superar essa complexidade, o professor deve buscar estratégias de ensino e aprendizagem que aproximem a vida da escola, interagindo com seus alunos, descobrindo seus interesses e dando-lhes autonomia para que consigam pensar matematicamente. Nesse processo de pôr em prática a inserção das tecnologias digitais móveis na sala de aula, descobrimos um universo de possibilidades de transformar o ambiente educativo em "um conjunto de espaços ricos de aprendizagens significativas, presenciais e digitais, que motivem os alunos a aprender ativamente, a pesquisar o tempo todo, a serem proativos, a saber tomar iniciativas e interagir" (MORAN, 2013, p. 31).

Ao desenvolver um trabalho de pesquisa e investigação com os alunos, enfrentamos a superação de nossos próprios medos e limitações. Nós sabemos que mudar é um processo 
lento que gera conflitos internos entre o que aprendemos, ensinamos e a educação que desejamos, mas possibilita a experimentação de práticas pedagógicas reais, que tão logo recebemos os frutos, como podemos nos emocionar nas palavras desse aluno:

$\mathrm{Eu}$ gostei muito de fazer esse trabalho, pois nos permitiu enxergar a matemática de uma forma diferente, e nos permitiu ver que algumas pessoas realmente têm medo de contas, e às vezes nem sabem que algumas são super fáceis, basta paciência e boa vontade para resolver. Acho que todos os profs deveriam seguir o exemplo da minha sora de matemática doidinha, que sempre propõe os melhores trabalhos e sempre tenta incentivar e cativar cada um de nós a ser melhor a cada dia. Para ensinar matemática tem que gostar, tem que pensar em ideias e formas de deixar tudo menos maçante. Gostei muito da oportunidade de gravar esse vídeo, me permitiu enxergar a matemática com outros olhos! (MITCHELL, 2016)

As respostas recebidas dos alunos demonstraram o quanto a afetividade faz parte do processo de ensino e aprendizagem, a empatia, o olhar o outro com carinho e perceber as suas potencialidades. Com certeza este estudo deixa marcado no coração e na história da educadora e de seus educandos os momentos que partilharam juntos tanto no ambiente escolar como no digital, possibilitando um novo olhar para a Matemática com a inserção das tecnologias, que transcendeu os muros da escola e até a nossa própria imaginação. A seguir, apresentaremos algumas considerações sobre a pesquisa.

\section{Considerações}

Fundamentados nos estudos de Ponte, Brocardo e Oliveira (2016) realizamos essa pesquisa com o objetivo de discutir o potencial de uma prática pedagógica nas aulas de Matemática. $\mathrm{Na}$ visão desses autores uma investigação não consiste em trabalhar com problemas difíceis, mas com situações que nos interpelam e provocam a busca por respostas. Para entender porque investigar se constitui em uma poderosa forma de construir conhecimento, propomos aos estudantes de uma turma de nono ano, do Ensino Fundamental, estratégias de ensino e aprendizagem utilizando smartphones, o site de rede social Facebook, o aplicativo WhatsApp e o software de geometria dinâmica GeoGebra.

No desenvolvimento das práticas pedagógicas, seguimos os três passos delineados por Ponte, Brocardo e Oliveira que consistem em: introdução da tarefa, realização da investigação e discussão dos resultados. Essas etapas foram realizadas da seguinte forma - no início a professora conversou com a turma e expôs a proposta de trabalho. Na segunda etapa, os alunos se dividiram em grupos. Por fim, a terceira etapa representou a divulgação dos resultados para a turma e as implicações emergentes nesse processo. 
No momento em que os estudantes são desafiados a realizar uma investigação com a inserção do smartphone na aula de Matemática, alguns critérios precisam ser estabelecidos para que o êxito do trabalho seja atingido. Diferente das aulas tradicionais, a atividade de investigação exige do educador maior flexibilidade, pois professores e alunos estão construindo juntos estratégias que demandam tempo e espaço para a discussão das ideias, elaboração de um roteiro, parceria entre os envolvidos, orientação nas divergências e direcionamento quando necessário.

A motivação, no contexto escolar, é essencial para a construção do conhecimento. Podemos observar nas falas dos sujeitos o encantamento ao produzir um vídeo sobre formas geométricas e as descobertas do grupo reconhecendo que a Matemática faz parte das suas vidas e não se resume apenas a cálculos no caderno. Em outra produção de vídeo, desafiamonos com um recurso didático pouco explorado nas escolas, a inclusão da literatura nas aulas de Matemática, instigando a turma para que falasse sobre os medos que essa disciplina representa e criando a partir dessas histórias, a sua própria história com personalidade e criatividade. O que tornou tudo mais fascinante é que podemos desenvolver por meio de histórias os conceitos matemáticos e construí-los com um software de geometria dinâmica, estimulando o pensamento algorítmico dos estudantes.

As dramatizações elaboradas com efeitos especiais representam o envolvimento da turma quando inserimos no ambiente escolar recursos que os alunos dominam com facilidade quando fazem uso para entretenimento. Percebemos que a interação entre professores e alunos se diferencia, revelando uma nova prática pedagógica em que estabelecemos uma relação de confiança e parceria com nossos estudantes. O papel que o educador desempenha nesse processo é fundamental ao considerar questões que emergem do cotidiano dos alunos, buscando novos conhecimentos sobre outros softwares e aplicativos.

Dessa maneira, compreendemos que para desenvolver uma nova prática pedagógica, precisamos abandonar velhas concepções e nos lançar em ações que priorizem não só a alfabetização tecnológica, mas também permitam expandir os conhecimentos em atividades de investigação. Nesse processo, em que nos propomos a estudar, refletir e discutir sobre a integração das tecnologias digitais às aulas, recebemos dos alunos o reconhecimento de que a Matemática está presente em todos os segmentos das nossas vidas. Para tanto, a turma criou a hashtag "\#DaBhaskaraPraVida" representando o quanto essa interação transcendeu os espaços presenciais e digitais. 


\section{Referências}

BELLONI, M. L. O que é mídia-educação. 3.ed. rev. Campinas, SP: Autores Associados, 2009.

BEHRENS, M. A. Projetos de aprendizagem colaborativa num paradigma emergente. In: MORAN, J. M.; MASETTO, M. T.; BEHRENS, M. A. Novas tecnologias e mediação pedagógica. 21.ed. rev. e atual. Campinas, SP: Papirus, 2013, p. 73-140.

BORBA, M. C.; PENTEADO, M. G. Informática e Educação Matemática. 4.ed. Belo Horizonte: Autêntica Editora, 2010.

ENZENSBERGER, H. M. O Diabo dos Números. 1.ed. São Paulo: Companhia das Letras, 2009.

FERREIRA, A. B. H. Dicionário Aurélio da Língua Portuguesa. 5.ed. Curitiba: Positivo, 2010.

IMBERNÓN, F. Formação docente e profissional: formar-se para a mudança e a incerteza. 9.ed. São Paulo: Cortez, 2011.

KENSKI, V. M. Tecnologias e tempo docente. Campinas: Papirus, 2013.

MENEZES, L. Matemática, Literatura e Aulas (2011). Disponível em:

$<$ http://www.esev.ipv.pt/mat1ciclo/Nova\%20pasta/_EM115_pp67-71_4f1d94c118b47_H.pdf >.

Acesso em: 22 nov. 2018.

MORAES, R.; GALIAZZI, M. C. Análise Textual Discursiva. 2.ed. rev. Ijuí: Editora Unijuí, 2011.

MORAN, J. M. Ensino e aprendizagem inovadores com apoio de tecnologias. In: MORAN, J. M.;

MASETTO, M. T.; BEHRENS, M. A. Novas tecnologias e mediação pedagógica. 21.ed. rev. e atual. Campinas, SP: Papirus, 2013, p. 11-72.

PONTE, J. P.; BROCARDO, J.; OLIVEIRA, H. Investigações Matemáticas na Sala de Aula. 3.ed. rev. ampl.; 2. reimp. Belo Horizonte: Autêntica Editora, 2016. 